\title{
Erratum zu: Amplitude of brain signals classify hunger status based on machine learning in resting-state fMRI
}

Arkan Al-Zubaidi, Alfred Mertins, Marcus Heldmann, Kamila Jauch-Chara, Thomas F. Münte

Erratum zu:

Kapitel 13 in: A. Maier et al. (Hrsg.), Bildverarbeitung für die Medizin 2018, Informatik aktuell, https://doi.org/10.1007/978-3-662-56537-7_13

An incorrect version of the article by Al-Zubaidi et al. was initially published. The original version has been retracted, and the correct version of the article has been published (under doi https://doi.org/10.1007/978-3-662-56537-7_13) online and in the print version of this book. The original version has been updated to indicate the retraction, and the correct version is now the version of record. 